\title{
Non-Invasive and Point-Of-Care Surface-Enhanced Raman Scattering (SERS)-based Breathalyzer for Mass Screening of Coronavirus Disease 2019 (COVID-19) under 5 Minutes
}

Shi Xuan Leong ${ }^{1 \#}$, Yong Xiang Leong ${ }^{1 \#}$, Emily Xi Tan ${ }^{1}$, Howard Yi Fan Sim${ }^{1}$, Charlynn Sher Lin $\mathrm{Koh}^{1}$, Yih Hong Lee ${ }^{1}$, Carice Chong ${ }^{1}$, Li Shiuan $\mathrm{Ng}^{1}$, Jaslyn $\mathrm{Ru}$ Ting Chen ${ }^{1}$, Desmond Wei Cheng Pang ${ }^{1}$, Lam Bang Thanh Nguyen ${ }^{1}$, Siew Kheng Boong ${ }^{1}$, Xuemei Han ${ }^{1}$, Ya-Chuan $\mathrm{Kao}^{1}$, Yi Heng Chua ${ }^{1}$, Gia Chuong Phan-Quang ${ }^{1,2}$, In Yee Phang ${ }^{2}$, Hiang Kwee Lee ${ }^{1}$, Mohammad Yazid Abdad ${ }^{3,4,5}$, Nguan Soon Tan ${ }^{6,7}$, Xing Yi Ling ${ }^{1 *}$

${ }^{1}$ Division of Chemistry and Biological Chemistry, School of Physical and Mathematical Sciences, Nanyang Technological University, Singapore, 637371, Singapore.

${ }^{2}$ Silver Factory Technology Pte. Ltd., Singapore, 169203, Singapore.

${ }^{3}$ Infectious Diseases Research Laboratory, National Centre for Infectious Diseases, Singapore, 308442, Singapore.

${ }^{4}$ Centre for Tropical Medicine and Global Health, Nuffield Department of Medicine, University of Oxford, Oxford, OX3 7LG, UK.

${ }^{5}$ Faculty of Tropical Medicine, Mahidol University, Bangkok, 10400, Thailand.

${ }^{6}$ Lee Kong Chian School of Medicine, Nanyang Technological University, Singapore, 308232, Singapore.

${ }^{7}$ School of Biological Sciences, Nanyang Technological University, Singapore, 637551, Singapore.

\# These authors contributed equally.

* To whom correspondence should be addressed. Email: xyling@,ntu.edu.sg 

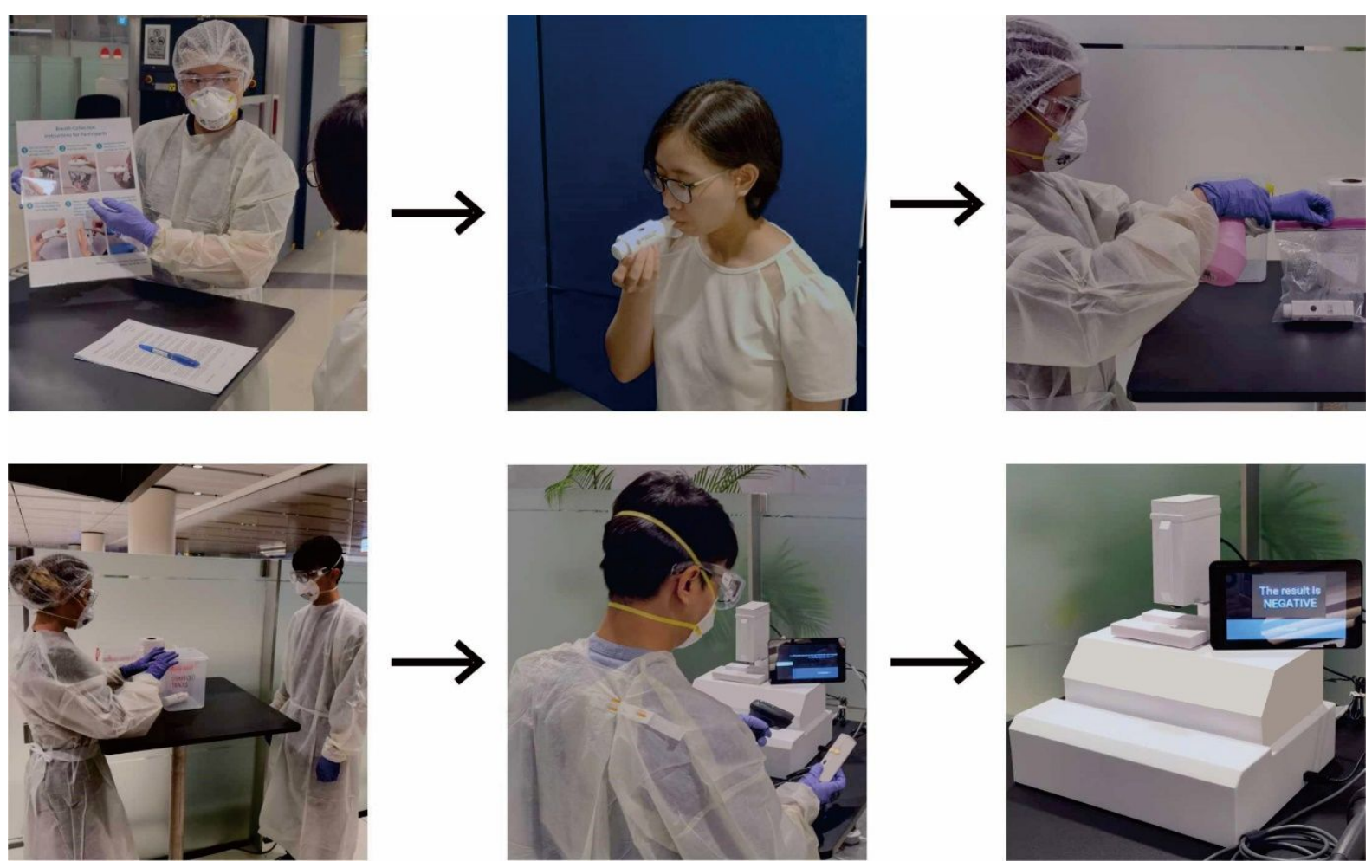

Figure S1. Digital images describing the participant recruitment workflow, which includes briefing the participant, breath sample collection, breathalyzer disinfection, SERS measurement and obtaining the prediction outcome. 

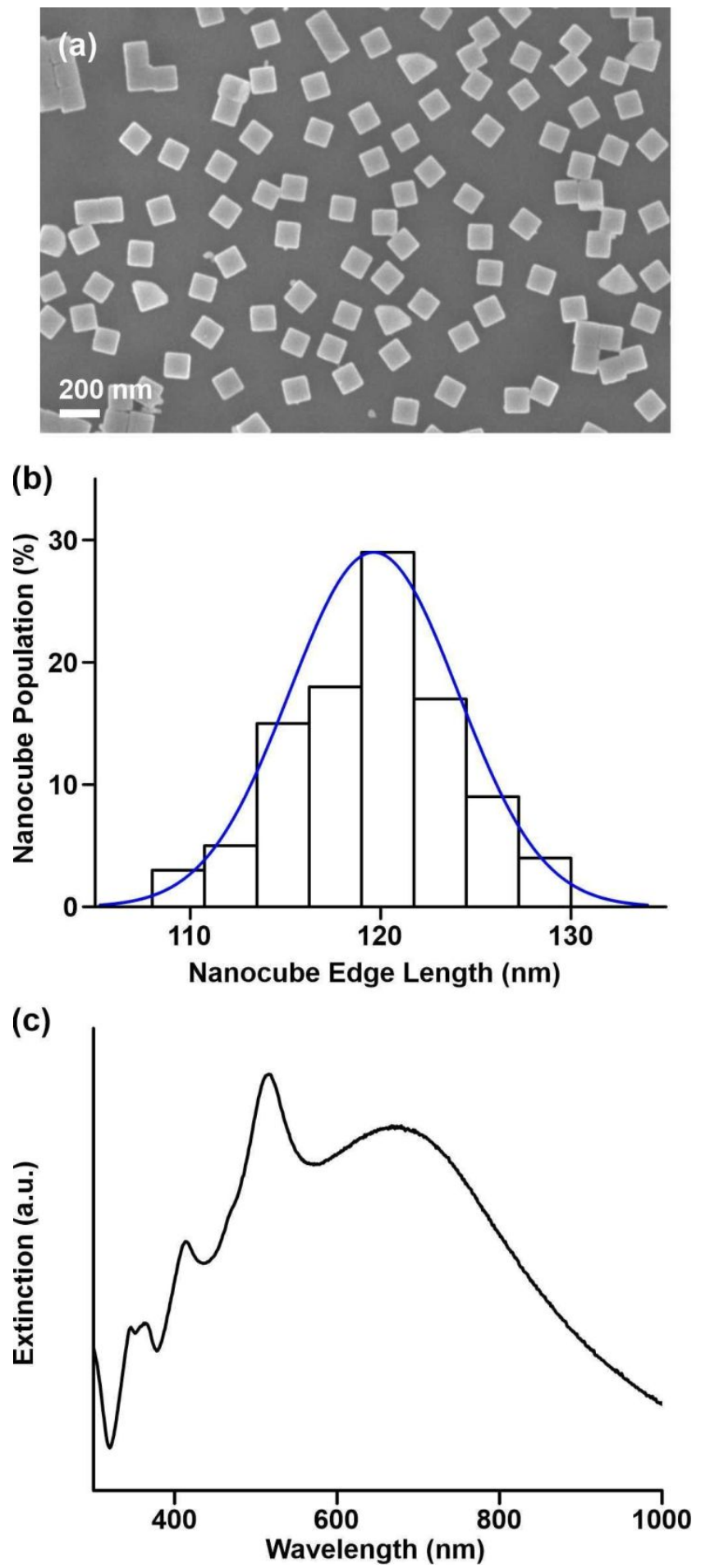

Figure S2. Characterization of synthesized Ag nanocubes. (a) SEM image of the Ag nanocubes. (b) Size distribution of the Ag nanocubes, with edge lengths of $120 \pm 5 \mathrm{~nm}$. (c) Extinction spectra of the Ag nanocubes, exhibiting clear plasmonic resonances across the entire visible light region. 
(A) SERS superprofiles

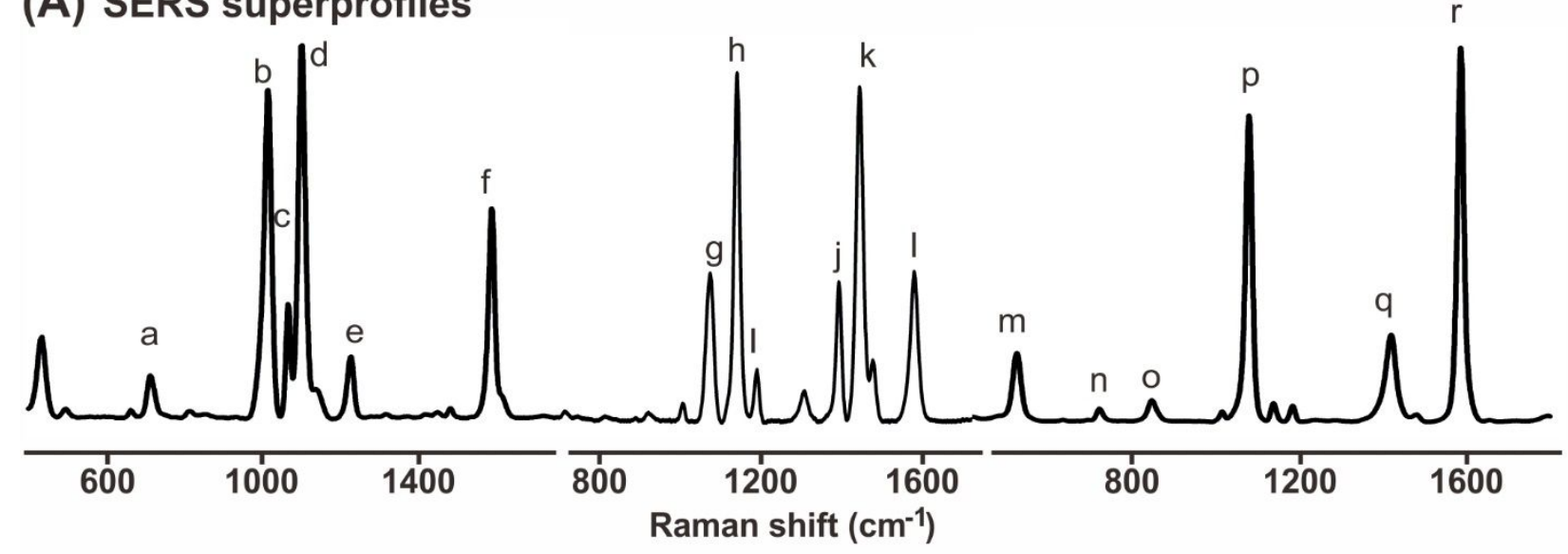

(B)

\begin{tabular}{|c|c|c|c|}
\hline \multicolumn{2}{|c|}{ Peak position } & $\begin{array}{l}\text { Experimental } \\
\left(\mathrm{cm}^{-1}\right)\end{array}$ & Assignment \\
\hline \multirow[t]{6}{*}{ MPY } & a & 714 & $v(C-S)$ \\
\hline & $\mathrm{b}$ & 1014 & Ring breathing \\
\hline & $\mathrm{c}$ & 1064 & $\delta(\mathrm{CH})$ \\
\hline & $d$ & 1100 & Ring breathing $+v(C-S)$ \\
\hline & $\mathrm{e}$ & 1224 & $\beta(\mathrm{CH})+\delta(\mathrm{NH})$ \\
\hline & $f$ & 1586 & $\mathrm{v}(\mathrm{C}=\mathrm{C})^{*}$ de-protonated pyridine \\
\hline \multirow[t]{6}{*}{ ATP } & $\mathrm{g}$ & 1075 & $v(C=C)+v(C-S)$ \\
\hline & $\mathrm{h}$ & 1143 & $\beta(C-H)+v(C-N)$ \\
\hline & $\mathrm{i}$ & 1186 & $\beta(\mathrm{C}-\mathrm{H})$ \\
\hline & j & 1393 & $v(N=N)+v(C-N)$ \\
\hline & $\mathrm{k}$ & 1441 & $v(N=N)+\beta(C-H)$ \\
\hline & 1 & 1580 & $v(C=C)$ \\
\hline \multirow[t]{6}{*}{ MBA } & $\mathrm{m}$ & 521 & $v(C-S)$ \\
\hline & $\mathrm{n}$ & 717 & $\mathrm{\gamma}(\mathrm{CCC})$ \\
\hline & o & 842 & $\delta(\mathrm{COO}-)$ \\
\hline & $\mathrm{p}$ & 1077 & Ring breathing $+v(C-S)$ \\
\hline & q & 1418 & $\mathrm{v}(\mathrm{COO}-)$ \\
\hline & r & 1586 & $v(C=C)$ \\
\hline
\end{tabular}

$v$, stretching; $\delta$, bending; $\rho$, rocking; $\beta, X-H$ bending (where $X$ is $C, N, O$ ); $y$, out of plane bending

Figure S3. SERS super-profile and assigned vibrational modes. (A) A representative SERS super-profile. (B) Vibrational mode assignments for key fingerprints in the super-profile. ${ }^{1-6}$ 


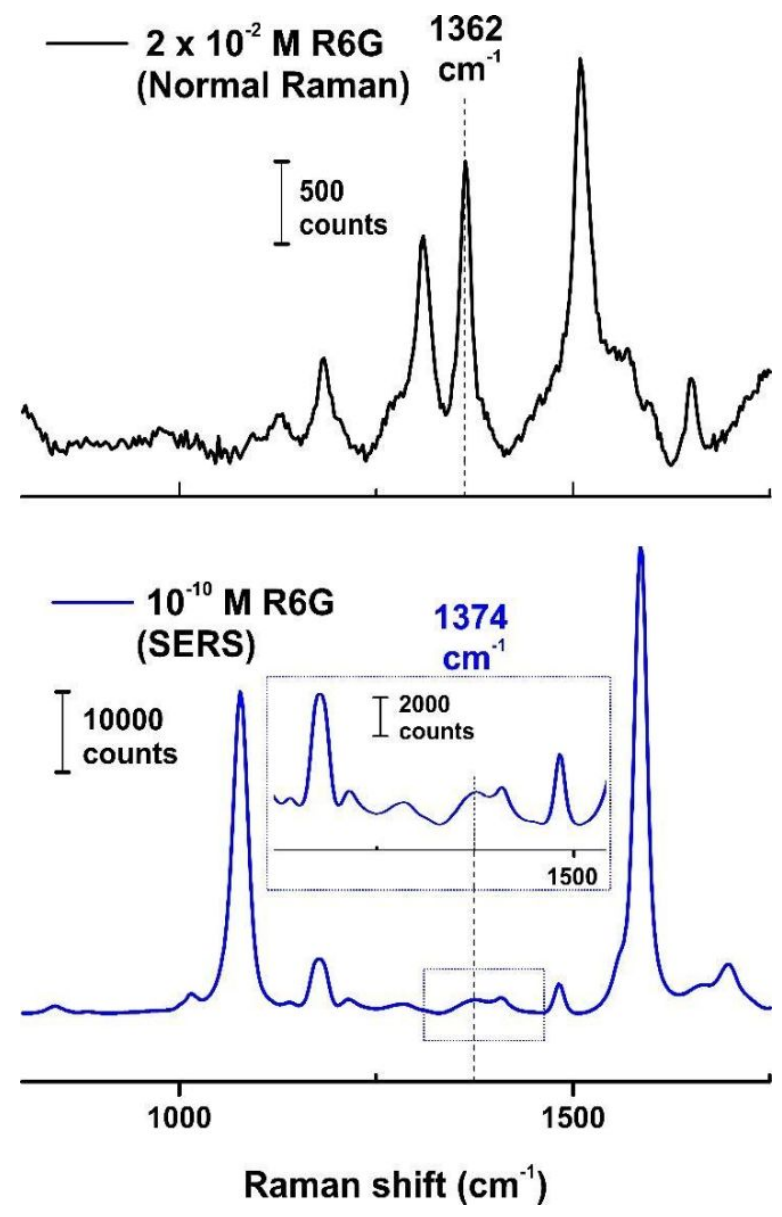

Figure S4. Determining the analytical enhancement factor (AEF) of our SERS sensor using Rhodamine 6G. The normal Raman spectrum of Rhodamine $6 \mathrm{G}\left(2 \times 10^{-2} \mathrm{M}\right)$ drop casted on an aluminum plate is shown in black while the SERS spectra of Rhodamine $6 \mathrm{G}\left(10^{-10} \mathrm{M}\right)$ drop casted on our SERS sensor is shown in blue. 
Supplementary Information 1. Calculation of analytical enhancement factor (AEF).

Using Rhodamine 6G (Figure S4),

$\mathrm{I}_{\mathrm{SERS}}=1269 \pm 44$ counts

$\mathrm{I}_{\text {Raman }}=1784 \pm 19$ counts

The AEF of our SERS sensor is given as:

$$
\begin{aligned}
\mathrm{AEF} & =\frac{\mathrm{I}_{\text {SERS }}}{\mathrm{I}_{\text {Raman }}} \times \frac{\mathrm{C}_{\text {Raman }}}{\mathrm{C}_{\text {SERS }}} \\
& =\frac{1269}{17.84} \times \frac{2 \times 10^{-2}}{10^{10}} \\
& =1.4 \times 10^{10}
\end{aligned}
$$

where $\mathrm{C}_{\mathrm{SERS}}$ and $\mathrm{C}_{\text {Raman }}$ are the concentrations of Rhodamine $6 \mathrm{G}$ measured using our SERS sensor $\left(10^{-10} \mathrm{M}\right)$ and normal Raman $\left(2 \times 10^{-2} \mathrm{M}\right)$ respectively, while $\mathrm{I}_{\text {SERS }}$ and $\mathrm{I}_{\text {Raman }}$ are the signal intensities recorded using SERS and normal Raman at their respective concentrations per unit time. 


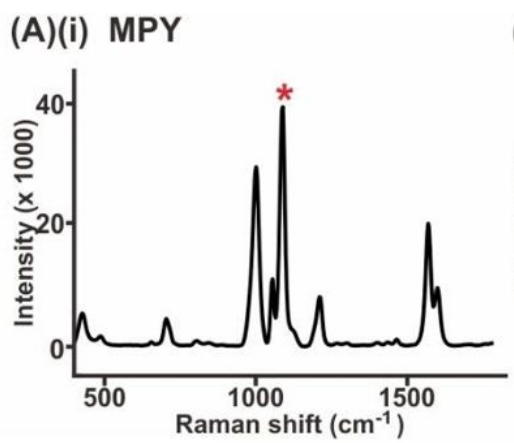

(ii) - Substrates 1-25 $=$ Substrates 76-100
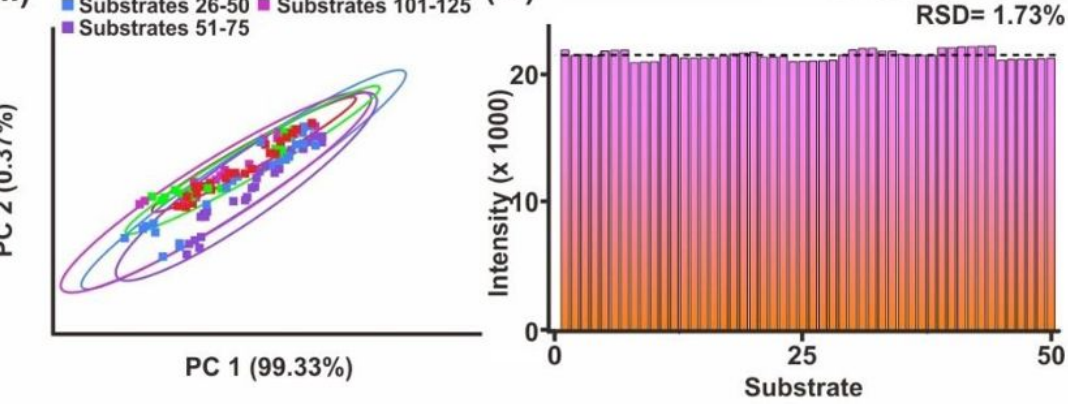

(B)(i) ATP
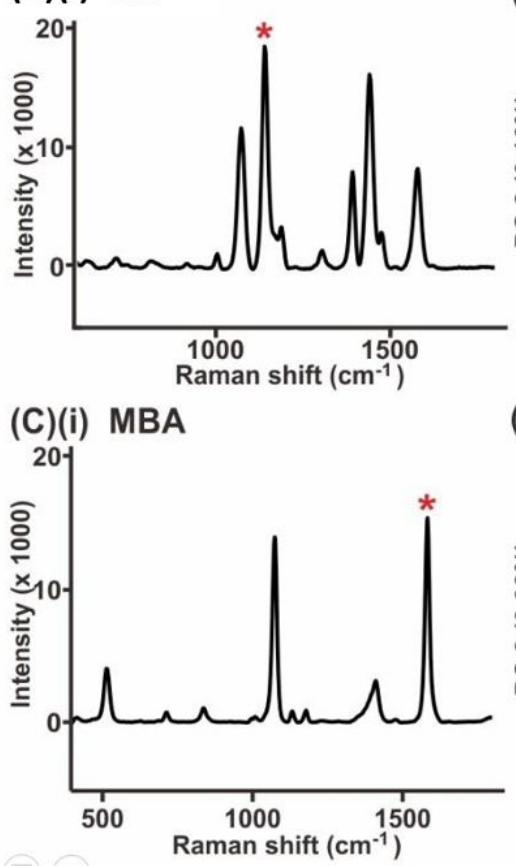

(ii) $=$ Substrates $1-25=$ Substrates $76-100$

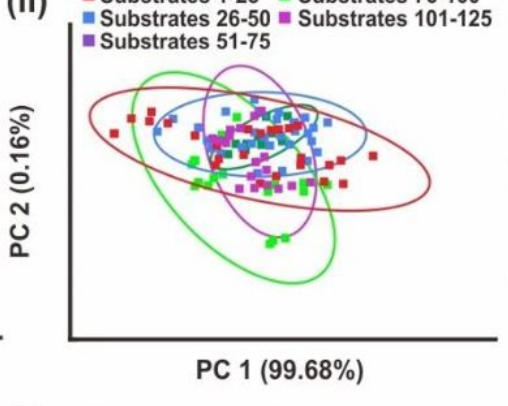

(ii) - Substrates 1-25 $=$ Substrates 76-100

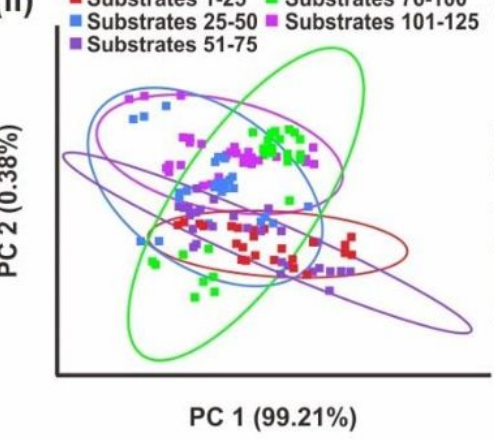

$12260 \pm 374$ counts

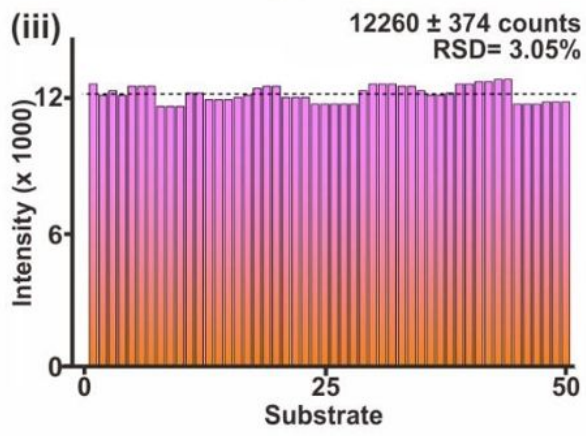

$7446 \pm 290$ counts RSD $=3.90 \%$

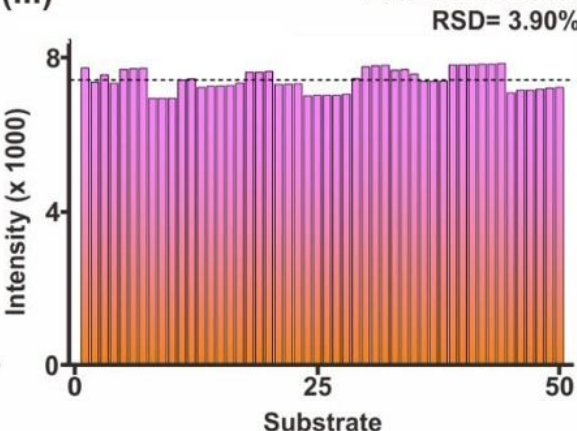

Figure S5. (i) Representative SERS spectra of each molecular receptor. (ii) PCA score plot (PC 1 vs. PC 2) of SERS spectra measured from 125 different sensor chips. The overlap of the spectral clusters indicates that the SERS signals are consistent and reproducible across different chips, with low chip-to-chip variation. (iii) comparison of the SERS intensity homogeneity for 50 different substrates for (A) MPY, (B) ATP, (C) MBA. The respective peak of each probe used to determine the SERS intensity homogeneity is indicated by an '*'. 

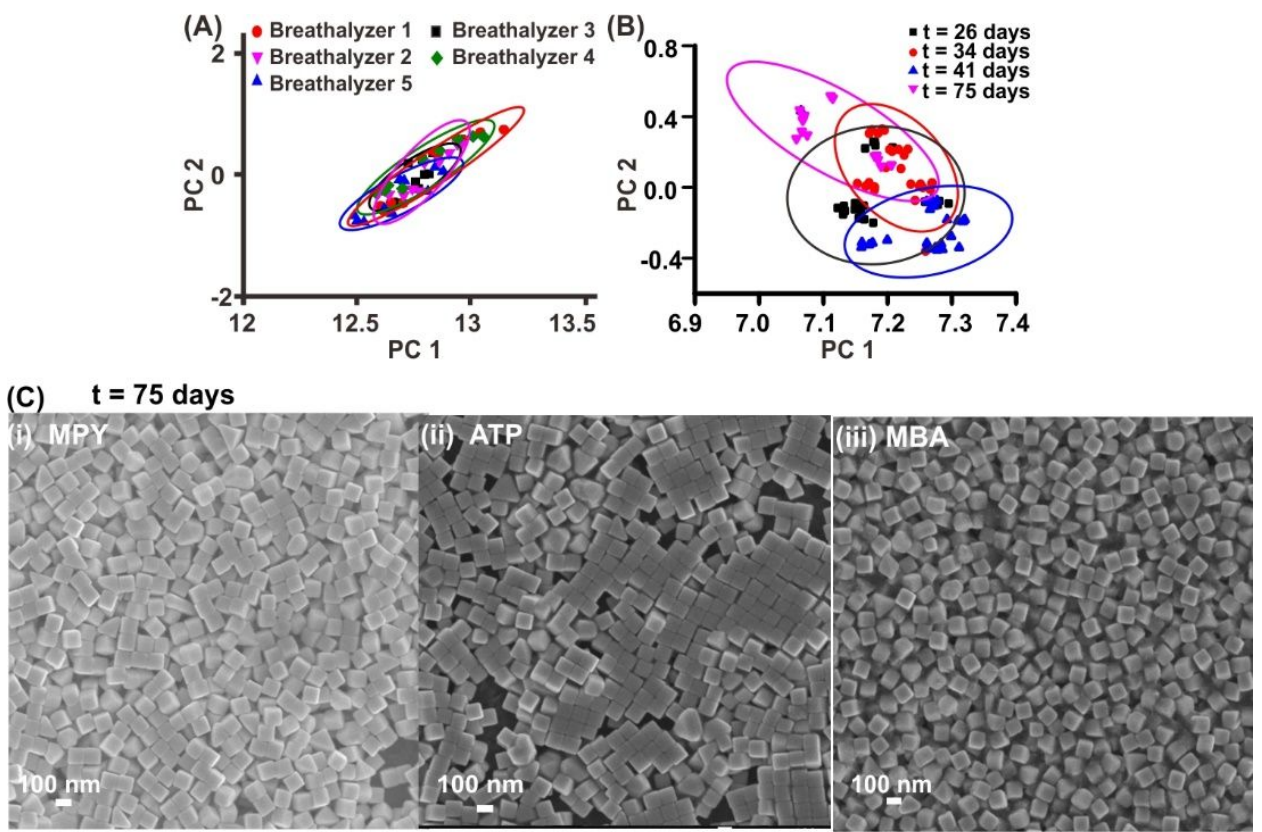

(D) After breath exposure

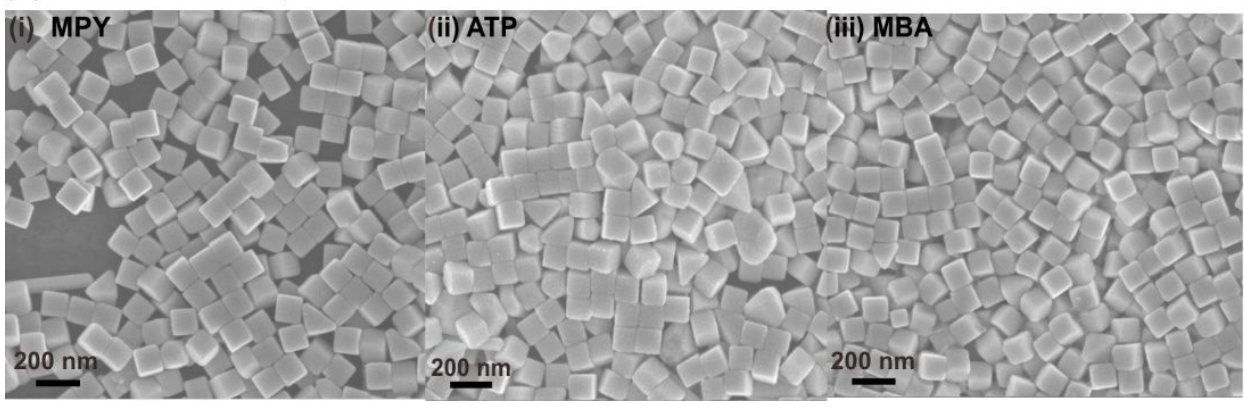

Figure S6. (A) PCA score plot (PC 1 vs. PC 2) of 6 assembled breathalyzers. Close overlap of the individual clusters illustrates the high signal reproducibility across different SERS chips even after breathalyzer integration. (B) PCA score plot (PC 1 vs. PC 2) of five as-fabricated SERS sensor chips at different time durations ( $t=26,34,41$ and 75 days) after initial fabrication. Close cluster overlap indicates that the functionalized Ag nanocubes remain chemically stable up to 2.5 months. It is of note that the measured 2.5 months is to affirm the utility of the SERS sensor chips for the duration of the clinical study and does not reflect the maximum shelf-life of the fabricated SERS chip. (C, D) SEM images of sensor chips at (C) $t$ $=75$ days and (D) after breath exposure for each of the molecular receptors, namely (i) MPY, (ii) ATP and (iii) MBA. The nanocubes maintain their shape integrity with no signs of etching due to oxidation. 


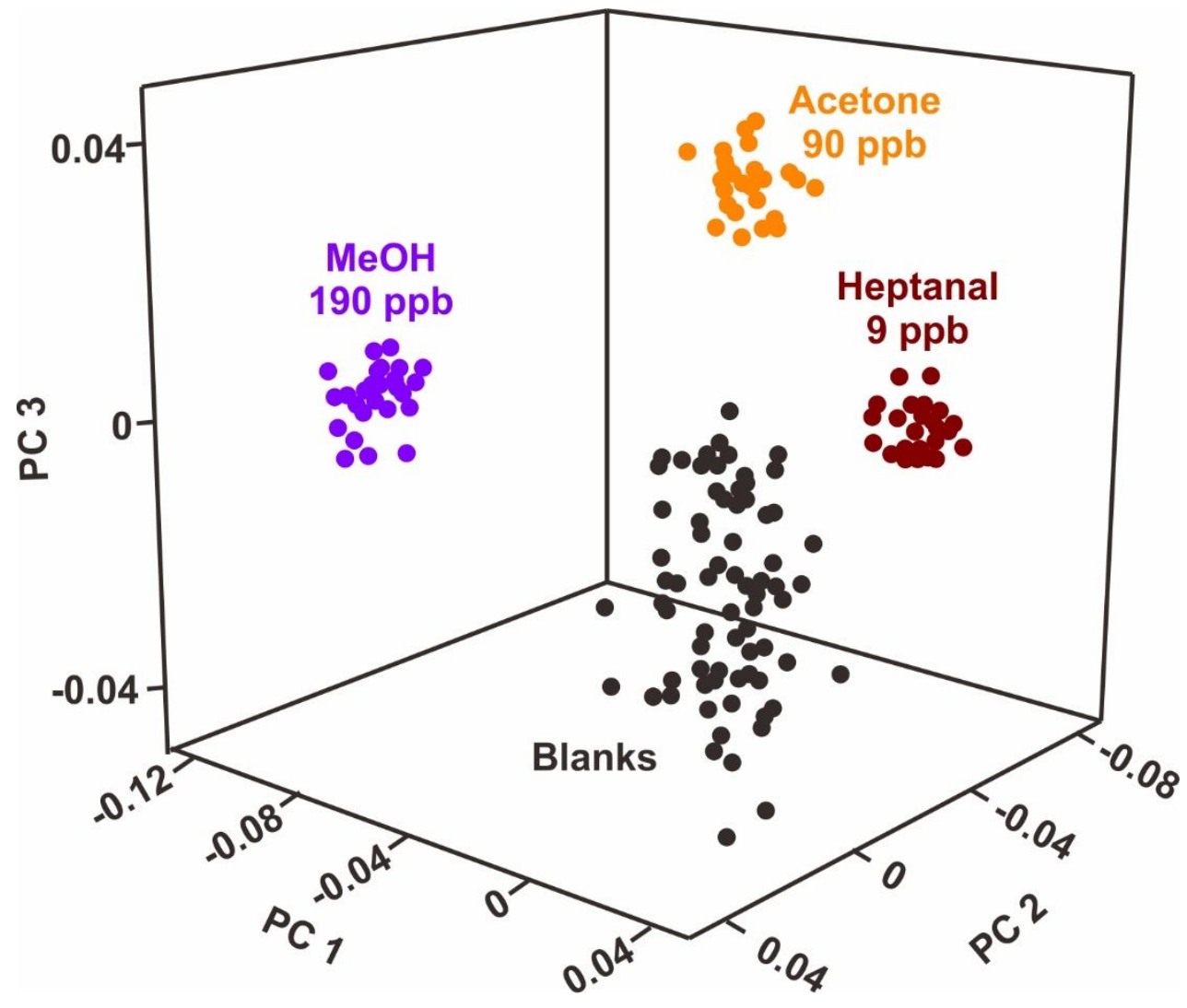

Figure S7. 3D principal component analysis (PCA) score plot (PC1 vs. PC2 vs. PC3) of SERS spectra collected in the absence (blanks) and presence of representative VOC vapors at their respective physiologically relevant levels. Each marker represents a SERS super-profile concatenated from MBA, MPY and ATP SERS spectra. The target VOCs investigated are heptanal (to represent aldehydes), acetone (to represent ketones) and methanol (to represent alcohols). Prior to PCA clustering, the SERS super-profiles are preprocessed using baseline, normalization and general least squares weighting (GLS) to remove clutter variance. The distinct and well-separated spectral clusters illustrate that methanol, acetone and heptanal each induces distinct and unique spectral changes to the receptors' SERS spectra, even at low ppb levels. This demonstrates the sensitivity of our SERS sensor to various VOCs. 


\section{(A) Participant 1}

(B) Participant 2

(C) Participant 3

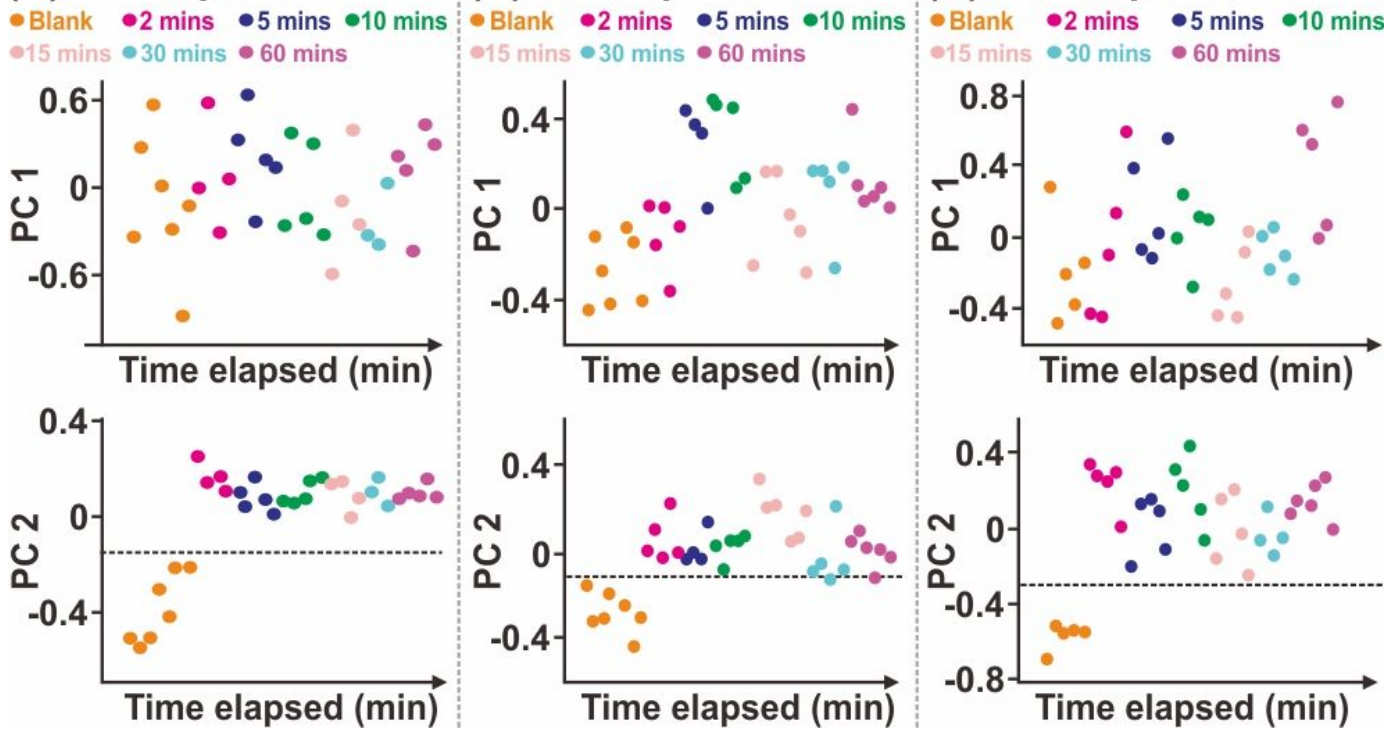

Figure S8. Determination of minimum incubation time for receptor-VOC interactions.

(A-C) PC scores vs. time elapsed after breath exhalation plots for 3 different participants. Upon breath exposure, SERS spectra were measured at fixed time intervals of $t=2,5,10,15,30,60$ and 90 mins. The SERS super-profiles at each time interval were analyzed using principal component analysis and compared with the blank super-profiles. Across all 3 runs, the change in PC 2 score assumes a logarithmic trend, with a distinct change after 2 mins of breath exposure and plateauing at about $\mathrm{t}=60$ mins. The PC 1 scores of all breath samples remains relatively constant throughout, which suggests that breath-induced spectral variation is largely captured in the $2^{\text {nd }} P C$. Thus, we establish 2 min as the minimum incubation time. 
Supplementary Information 2. Calculation of vapor concentrations for pure VOC vapors.

Each SERS sensor is incubated separately with $200 \mu \mathrm{L}$ of target analyte at $35^{\circ} \mathrm{C}$ in an enclosed $20 \mathrm{~mL}$ vial. SERS detection was performed after $6 \mathrm{~h}$ of incubation to allow vaporization to reach an equilibrium state. The saturated vapor concentration $\left(\mathrm{g} \mathrm{cm}^{-3}\right)$ is calculated using the ideal gas equation:

$$
\mathrm{PV}=\mathrm{nRT}
$$

where $\mathrm{P}$ is the saturated vapor pressure at $35^{\circ} \mathrm{C}(\mathrm{Pa}), \mathrm{V}$ is volume of enclosed vial $\left(\mathrm{cm}^{3}\right), \mathrm{R}$ is the universal gas constant $\left(8.314 \times 10^{6} \mathrm{~cm}^{3} \mathrm{~Pa} \mathrm{~K}^{-1} \mathrm{~mol}^{-1}\right)$ and $\mathrm{T}$ is the incubation temperature $(\mathrm{K})$.

Rearranging the equation,

$$
\text { Saturated concentration }\left(\mathrm{g} \mathrm{cm}^{-3}\right)=\frac{\mathrm{V}}{\mathrm{RT}} \times \mathrm{MW}
$$

Where $\mathrm{MW}$ is the molecular weight of the target analyte $\left(\mathrm{g} \mathrm{mol}^{-1}\right)$.

The saturated concentration can be converted from $\mathrm{g} \mathrm{cm}^{-3}$ to $\mathrm{ppm}$ by the following relationship, Saturated concentration $(\mathrm{ppm})=$ Saturated concentration $\left(\mathrm{g} \mathrm{cm}^{-3}\right) \times 10^{6}$

Table S1. Respective saturated vapor concentrations of each analyte.

\begin{tabular}{cccc}
\hline Compound & MW $\left(\mathrm{g} \mathrm{mol}^{-1}\right)$ & $\begin{array}{c}\text { Saturated vapor } \\
\text { pressure }(\mathrm{Pa})\end{array}$ & $\begin{array}{c}\text { Saturated vapor } \\
\text { concentration (ppm) }\end{array}$ \\
\hline ethanal & 44.05 & 143,280 & 2465 \\
heptanal & 100.21 & 569 & 22 \\
octanal & 128.212 & 80 & 4 \\
acetone & 58.08 & 37,519 & 851 \\
methanol & 32.04 & 21,697 & 271 \\
\hline water & 18.02 & 5,626 & 40 \\
\hline
\end{tabular}


Table S2. Summary of test statistics for peak intensity changes among blanks, COVID-positive and COVID-negative.

\begin{tabular}{|c|c|c|c|}
\hline Comparison & $\mathrm{U}$ & $\mathrm{Z}$ & Probability $>|U|$ \\
\hline \multicolumn{4}{|c|}{ MPY $1617 \mathrm{~cm}^{-1} / 1586 \mathrm{~cm}^{-1}$} \\
\hline Blank vs. COVID-negative & 0 & -18.15465 & $1.17973 \times 10^{-73}$ \\
\hline Blank vs. COVID-positive & 0 & -11.83178 & $2.67425 \times 10^{-32}$ \\
\hline COVID-positive vs. COVID negative & 4078 & -9.30333 & $1.36118 \times 10^{-20}$ \\
\hline \multicolumn{4}{|c|}{ DMAB $1143 \mathrm{~cm}^{-1} / 1075 \mathrm{~cm}^{-1}$} \\
\hline Blank vs. COVID-negative & 29326 & -14.83242 & $9.04155 \times 10^{-50}$ \\
\hline Blank vs. COVID-positive & 8771 & -2.67483 & 0.00748 \\
\hline COVID-positive vs. COVID negative & 21821 & 4.79878 & $1.59638 \times 10^{-6}$ \\
\hline \multicolumn{4}{|c|}{ DMAB $1186 \mathrm{~cm}^{-1} / 1075 \mathrm{~cm}^{-1}$} \\
\hline Blank vs. COVID-negative & 4021 & -16.44439 & $9.20048 \times 10^{-61}$ \\
\hline Blank vs. COVID-positive & 1660 & -8.41441 & $3.94867 \times 10^{-17}$ \\
\hline COVID-positive vs. COVID negative & 22441 & 8.2616 & $2.22045 \times 10^{-16}$ \\
\hline \multicolumn{4}{|c|}{ DMAB $1393 \mathrm{~cm}^{-1} / 1075 \mathrm{~cm}^{-1}$} \\
\hline Blank vs. COVID-negative & 48708 & -16.49396 & $4.05455 \times 10^{-61}$ \\
\hline Blank vs. COVID-positive & 12136 & -7.54075 & $4.67281 \times 10^{-14}$ \\
\hline COVID-positive vs. COVID negative & 67632 & 4.20121 & $2.65494 \times 10^{-5}$ \\
\hline \multicolumn{4}{|c|}{ DMAB $1441 \mathrm{~cm}^{-1} / 1075 \mathrm{~cm}^{-1}$} \\
\hline Blank vs. COVID-negative & 32088 & -13.89048 & $7.23536 \times 10^{-44}$ \\
\hline Blank vs. COVID-positive & 7859 & -3.65652 & $2.55667 \times 10^{-4}$ \\
\hline COVID-positive vs. COVID negative & 20555 & 3.67522 & $2.37645 \times 10^{-4}$ \\
\hline \multicolumn{4}{|c|}{ MBA $521 \mathrm{~cm}^{-1} / 1077 \mathrm{~cm}^{-1}$} \\
\hline Blank vs. COVID-negative & 19015 & 5.71197 & $1.1678 \times 10^{-8}$ \\
\hline Blank vs. COVID-positive & 4331 & 9.54477 & $1.125 \times 10^{-30}$ \\
\hline COVID-positive vs. COVID negative & 16276 & 2.36422 & $1.807 \times 10^{-2}$ \\
\hline
\end{tabular}


Table S3. Comparison of experimental and DFT simulated peak intensities for $v(C S)$ mode relative to the ring breathing mode of MBA.

\section{$\underline{\text { Experimental }}$}

\begin{tabular}{lcc}
\hline & \multicolumn{2}{c}{ Peak intensity (a.u.) } \\
& $\begin{array}{l}\mathbf{v}(\mathbf{C S}) \text { at } \mathbf{5 2 1} \mathbf{~ c m}^{-\mathbf{1}} / \\
\text { ring breathing at } \mathbf{1 0 7 7} \mathbf{c m}^{-\mathbf{1}}\end{array}$ & $\begin{array}{c}\text { \% Change with } \\
\text { analyte incubation }\end{array}$ \\
\hline MBA only & $0.2451 \pm 0.0318$ & - \\
\hline MBA-acetone & $0.2111 \pm 0.0202$ & $\mathbf{- 1 3 . 9 1 \%}$ \\
\hline MBA-ethanal & $0.1601 \pm 0.006$ & $\mathbf{- 3 4 . 7 1 \%}$ \\
\hline MBA-heptanal & $0.2445 \pm 0.0170$ & $\mathbf{- 0 . 2 8 \%}$ \\
\hline MBA-octanal & $0.2160 \pm 0.0109$ & $\mathbf{- 1 1 . 9 1 \%}$ \\
\hline MBA-MeOH & $0.2659 \pm 0.0323$ & $+\mathbf{8 . 4 5 \%}$ \\
\hline MBA-water & $0.3063 \pm 0.0061$ & $+\mathbf{2 4 . 9 5 \%}$ \\
\hline
\end{tabular}

\section{$\underline{\text { DFT simulated }}$}

Peak intensity (a.u.)

\begin{tabular}{lcccc} 
& $\begin{array}{c}\mathbf{v}(\mathbf{C S}) \mathbf{a t} \\
\mathbf{2 9 6} \mathbf{c m}^{-\mathbf{1}}\end{array}$ & $\begin{array}{c}\text { Ring breathing } \\
\text { at } \mathbf{1 0 9 9} \mathbf{c m}^{-\mathbf{1}}\end{array}$ & $\begin{array}{c}\mathbf{v ( C S )} / \\
\text { ring breathing }\end{array}$ & $\begin{array}{c}\text { \% Change } \\
\text { with } \\
\text { analyte }\end{array}$ \\
\hline MBA only & 648.8 & 4053.4 & 0.1600 & - \\
\hline MBA-acetone & 35125.1 & 222790.5 & 0.1577 & $\mathbf{- 1 . 4 8} \%$ \\
\hline MBA-ethanal & 34160.4 & 216723.4 & 0.1576 & $\mathbf{- 1 . 5 0 \%}$ \\
\hline MBA-heptanal & 38964.9 & 244067.1 & 0.1596 & $\mathbf{- 0 . 2 3 \%}$ \\
\hline MBA-octanal & 25947.8 & 228943 & 0.1133 & $\mathbf{- 2 9 . 1 7 \%}$ \\
\hline MBA-MeOH & 46121.9 & 218295.6 & 0.2113 & $+\mathbf{3 2 . 0 3 \%}$ \\
\hline MBA-water & 29796.6 & 167335.1 & 0.1781 & $+\mathbf{1 1 . 2 7 \%}$ \\
\hline
\end{tabular}



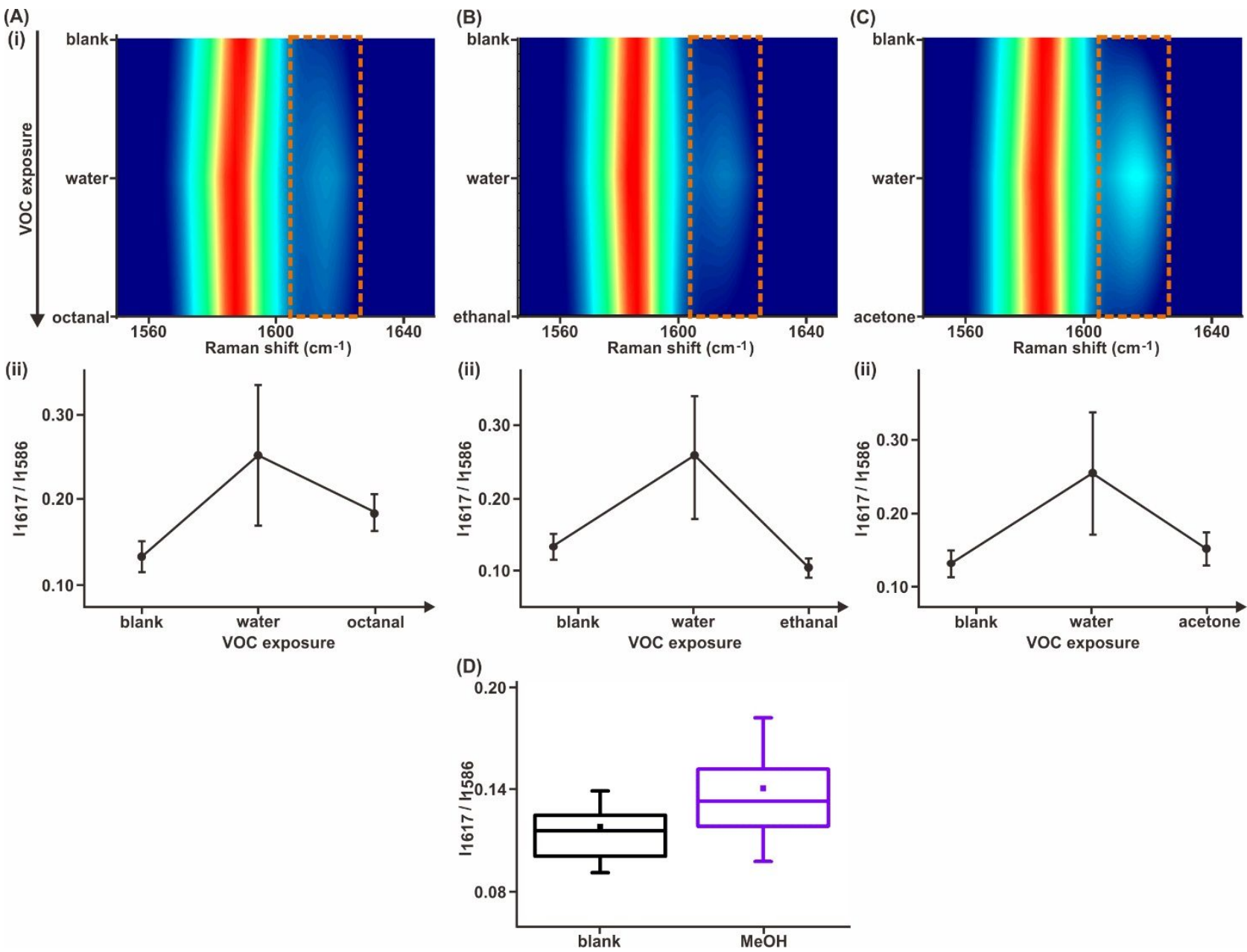

Figure S9. Additional MPY spectral analysis of pure analyte vapors. (A-C) (i) Evolution of $1550-1650 \mathrm{~cm}^{-1}$ spectral region, normalized to the $1586 \mathrm{~cm}^{-1}$ peak intensity upon exposure to water vapor and with subsequent exposure to (A) octanal, (B) ethanal, and (C) acetone. (ii) Corresponding $\mathrm{I}_{1617 \mathrm{~cm}-1} / \mathrm{I}_{1586 \mathrm{~cm}-1}$ peak intensity ratios at different stages of exposure. (D) Box plot of $\mathrm{I}_{1617 \mathrm{~cm}-1} / \mathrm{I}_{1586 \mathrm{~cm}-1}$ peak intensity ratios before and after $\mathrm{MeOH}$ exposure. 

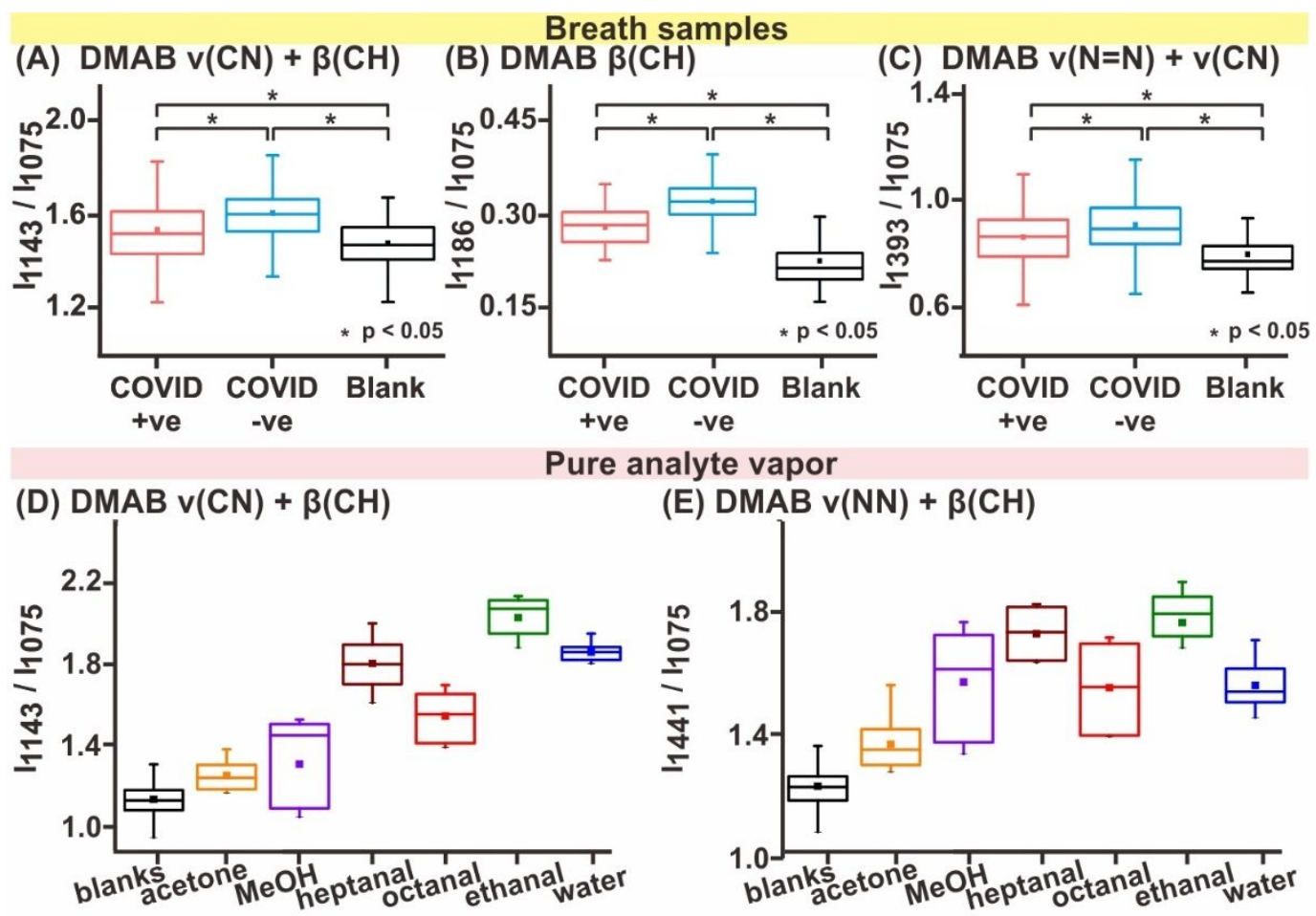

Figure S10. Additional ATP spectral analysis of collected breath samples and pure analyte vapors. (A-C) Boxplots comparing peak intensity ratios between blanks, COVIDpositive and COVID-negative samples. (D-E) Boxplots comparing peak intensity ratios between blanks and the respective pure analyte vapor. 


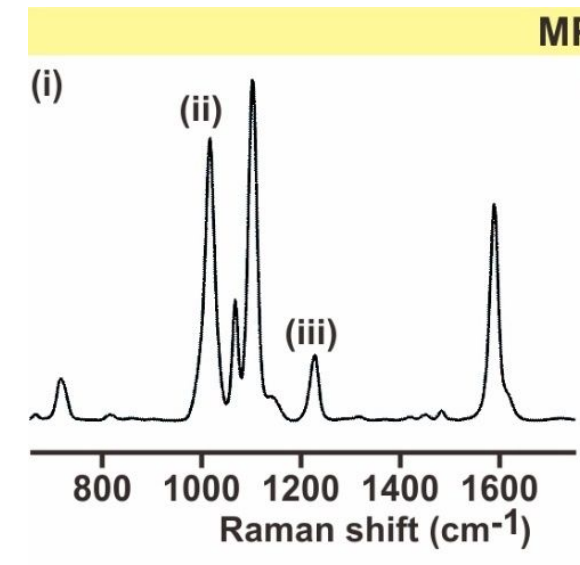

(iii)

$\beta(\mathrm{CH})+\delta(\mathrm{NH})$,

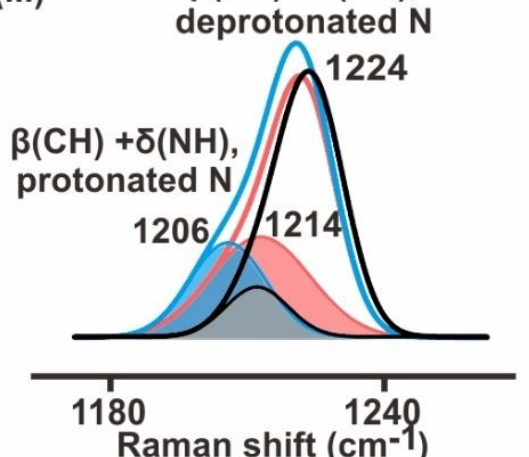

Raman shift (cm-1)
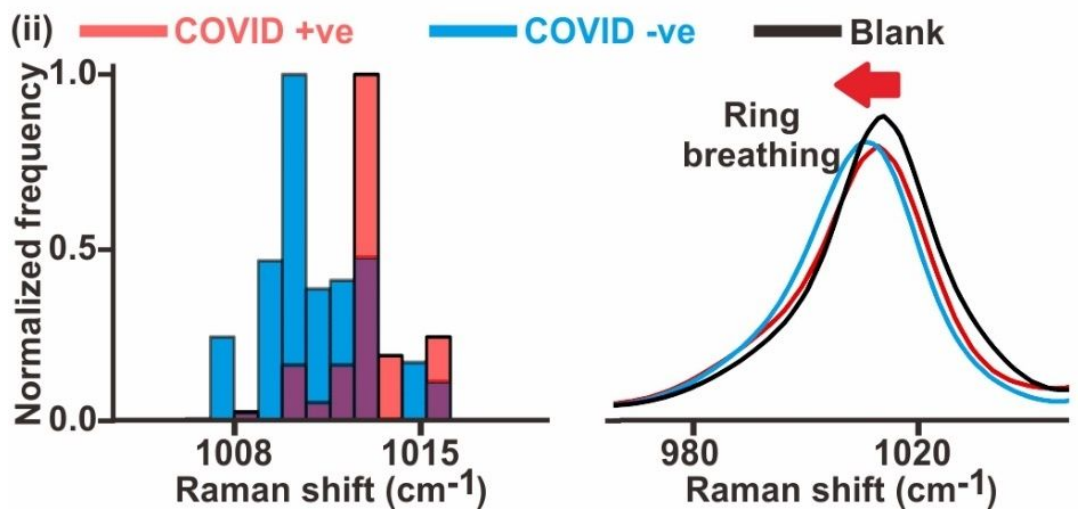

Figure S11. MPY spectral differences. (i) Representative MPY SERS spectra. Peaks of statistical difference between COVID-positive and COVID-negative individuals are indicated by (ii) - (iii). (ii) MPY ring breathing mode indexed at $1014 \mathrm{~cm}^{-1}$ red-shifts upon breath exposure, with COVID-negative individuals exhibiting a larger red-shift in general, as indicated by the histogram (left). (iii) COVID-negative individuals cause a larger intensification of the shoulder peak indexed to $\mathrm{CH}$ bending coupled with $\mathrm{NH}$ bending $\beta(\mathrm{CH})$ $+\delta(\mathrm{NH})$ with protonated $\mathrm{N}$ compared to COVID-positive individuals. 


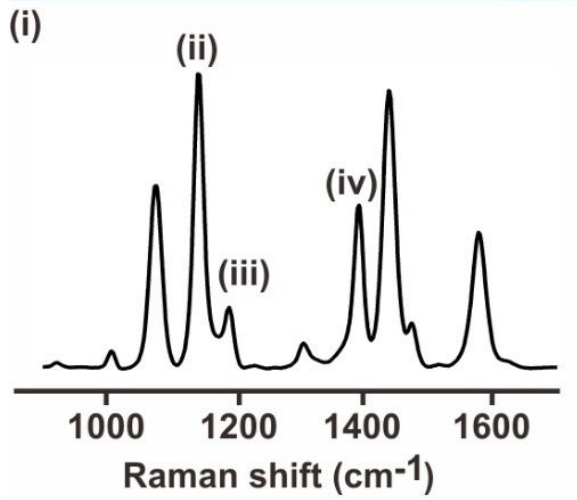

(iii) DMAB $\beta(\mathrm{CH})$

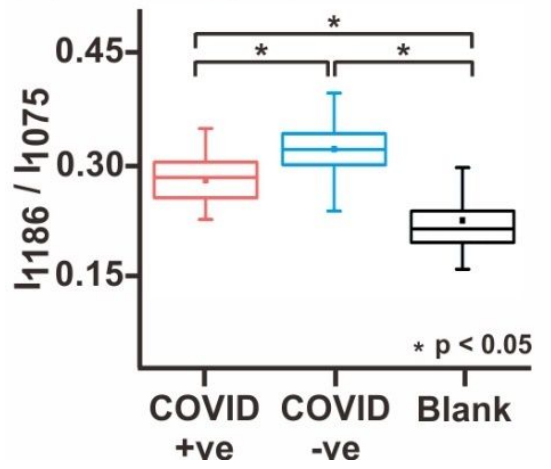

(ii) $\mathrm{DMAB} v(\mathrm{CN})+\beta(\mathrm{CH})$

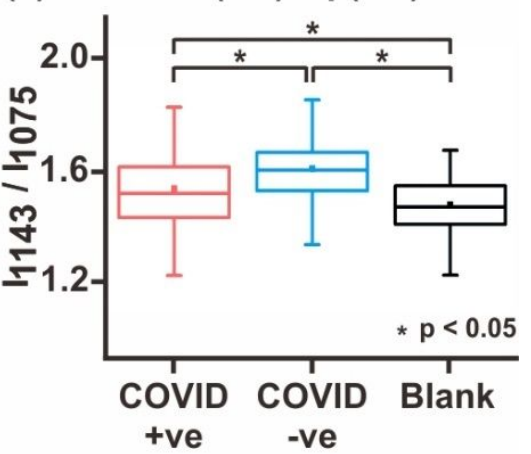

(iv) $\mathrm{DMAB} v(\mathrm{~N}=\mathrm{N})+\mathrm{v}(\mathrm{CN})$

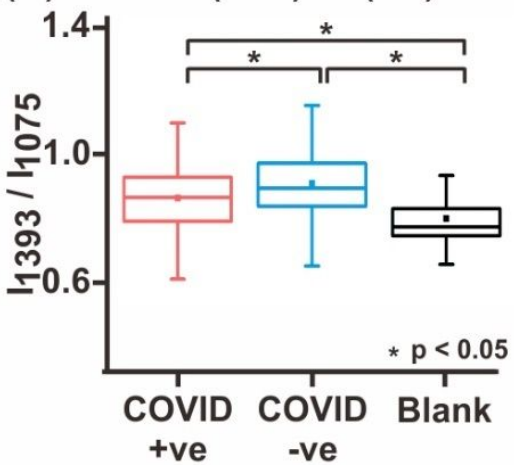

Figure S12. ATP spectral differences. (i) Representative ATP SERS spectra. Peaks of statistical difference between COVID-positive and COVID-negative individuals are indicated by (ii) - (iv). As discussed in the main text, ATP is known to undergo laser-induced dimerization to form DMAB, with characteristic DMAB peaks observed at 1143, 1186 and $1393 \mathrm{~cm}^{-1}$. (ii-iv) Boxplots comparing peak intensity ratios between blanks, COVID-positive and COVID-negative samples for (ii) DMAB CN stretching coupled with $\mathrm{CH}$ stretching $v(\mathrm{CH})$, (iii) DMAB $\mathrm{CH}$ bending $\beta(\mathrm{CH})$ and (iv) $\mathrm{DMAB} C \mathrm{~N}$ stretching coupled with $\mathrm{N}=\mathrm{N}$ stretching $v(\mathrm{NN})$. As highlighted in the main text, the DMAB-associated peaks intensify upon breath exposure, with COVID-negative samples inducing a larger increase than COVID-positive samples. All statistical significances, determined by the Mann-Whitney rank sum test at $p<$ 0.05 level, is indicated by *. For all box plots, the mean and median are represented by the square box symbol and horizontal line respectively. The main box covers the lower to upper quartiles while the whiskers are extended to cover all data points that lie within \pm 1.5 interquartile range. 


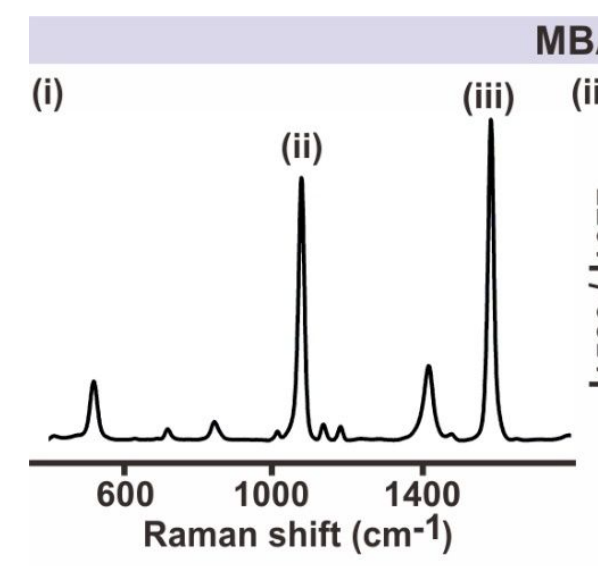

MBA

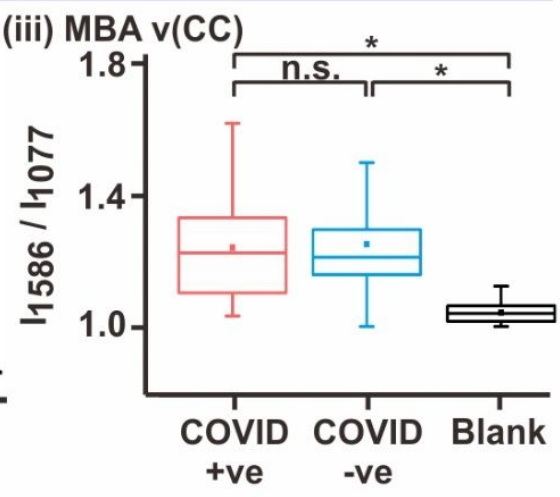

(ii) MBA ring breathing
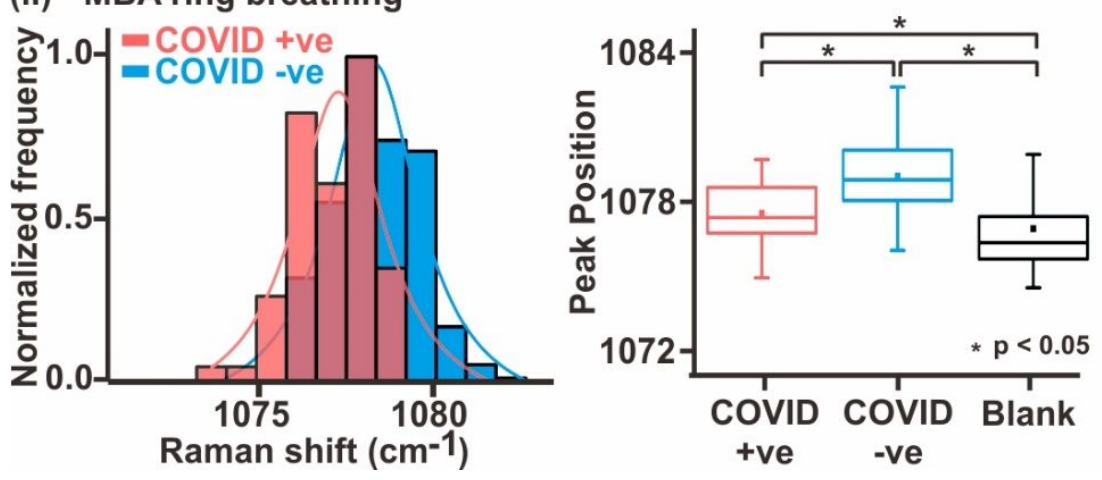

Figure S13. MBA spectral differences. (i) Representative MBA SERS spectra. Spectral regions that undergo changes upon breath exposure are indicated by (ii) - (iv). (ii) COVIDpositive samples cause an increase in intensity of MBA COO- bending $\delta(\mathrm{COO}-)$ mode indexed at $842 \mathrm{~cm}^{-1}$ while there are negligible changes for COVID-negative samples. (iii) MBA ring breathing mode indexed at $1077 \mathrm{~cm}^{-1}$ blue-shifts upon breath exposure, with COVID-negative individuals exhibiting a larger blue-shift in general, as indicated by the histogram (left). (iv) MBA CC stretching $v(\mathrm{CC})$ mode indexed at $1486 \mathrm{~cm}^{-1}$ intensifies upon breath exposure. However, there are negligible differences between COVID-positive and COVID-negative samples, as denoted by n.s. All statistical significances, determined by the Mann-Whitney rank sum test at $p<0.05$ level, is indicated by *. For all box plots, the mean and median are represented by the square box symbol and horizontal line respectively. The main box covers the lower to upper quartiles while the whiskers are extended to cover all data points that lie within \pm 1.5 interquartile range. 
Table S4. Sensitivity and specificity metrics for each of the 50 PLSDA iterations.

\begin{tabular}{|c|c|c|}
\hline Model no. & Sensitivity (\%) & Specificity (\%) \\
\hline 1 & 89.19 & 100 \\
\hline 2 & 100 & 100 \\
\hline 3 & 100 & 100 \\
\hline 4 & 97.3 & 99.07 \\
\hline 5 & 94.59 & 100 \\
\hline 6 & 100 & 100 \\
\hline 7 & 94.59 & 99.53 \\
\hline 8 & 91.89 & 100 \\
\hline 9 & 100 & 100 \\
\hline 10 & 91.89 & 100 \\
\hline 11 & 91.89 & 100 \\
\hline 12 & 93.33 & 100 \\
\hline 13 & 100 & 100 \\
\hline 14 & 91.89 & 100 \\
\hline 15 & 100 & 100 \\
\hline 16 & 94.59 & 100 \\
\hline 17 & 97.3 & 99.53 \\
\hline 18 & 100 & 100 \\
\hline 19 & 94.59 & 100 \\
\hline 20 & 100 & 100 \\
\hline 21 & 94.59 & 100 \\
\hline 22 & 97.3 & 99.07 \\
\hline 23 & 100 & 100 \\
\hline 24 & 100 & 100 \\
\hline 25 & 97.3 & 100 \\
\hline 26 & 97.3 & 100 \\
\hline 27 & 97.3 & 100 \\
\hline 28 & 91.89 & 100 \\
\hline 29 & 100 & 100 \\
\hline 30 & 97.3 & 100 \\
\hline 31 & 94.59 & 100 \\
\hline 32 & 91.89 & 100 \\
\hline 33 & 97.3 & 100 \\
\hline 34 & 94.59 & 100 \\
\hline 35 & 100 & 100 \\
\hline 36 & 94.59 & 100 \\
\hline 37 & 97.3 & 100 \\
\hline 38 & 93.33 & 100 \\
\hline 39 & 91.89 & 100 \\
\hline 40 & 100 & 99.53 \\
\hline 41 & 94.59 & 100 \\
\hline 42 & 100 & 100 \\
\hline 43 & 97.3 & 100 \\
\hline 44 & 100 & 100 \\
\hline 45 & 100 & 100 \\
\hline 46 & 86.49 & 100 \\
\hline 47 & 94.59 & 100 \\
\hline 48 & 94.59 & 100 \\
\hline 49 & 100 & 100 \\
\hline 50 & 89.19 & 100 \\
\hline
\end{tabular}


Supplementary Information 3. Sample calculation of a model sensitivity and specificity.

Actual PCR Positive Actual PCR Negative

\begin{tabular}{|l|c|c|}
\cline { 2 - 3 } Predicted Positive & 71 & 0 \\
Predicted Negative & 3 & 427 \\
\hline
\end{tabular}

$$
\begin{gathered}
\text { Sensitivity }=\frac{\text { True Positive }}{\text { True Positive }+ \text { False Negative }} \\
=\frac{71}{71+3} \times 100 \% \\
=96 \%
\end{gathered}
$$$$
\text { Specificity }=\frac{\text { True Negative }}{\text { True Negative }+ \text { False Positive }}
$$$$
=\frac{427}{427+0} \times 100 \%
$$$$
=100 \%
$$ 


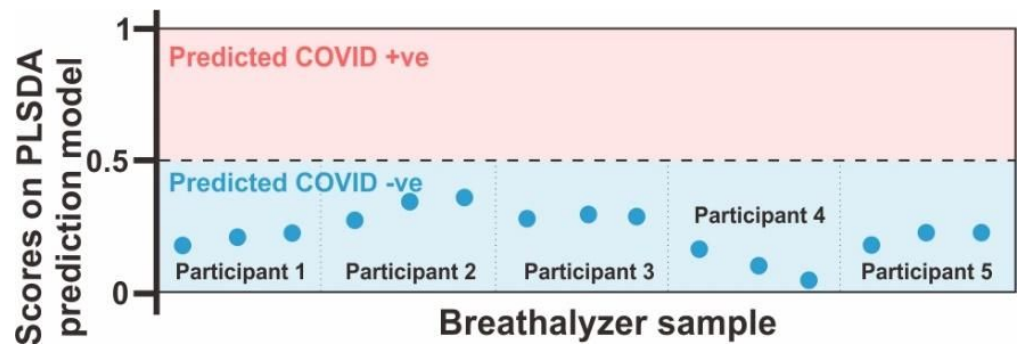

Figure S14. PLS-DA classification scores and outcomes across 5 participants. 3 breath samples were collected from each participant as replicates.

We affirm the reproducibility of our model by conducting a small laboratory-based replicate study with 5 COVID -ve volunteers (not included in the 501 sample size). Their predicted classification outcomes using 3 separate breath samples are all consistent and predicted correctly as COVID -ve. Hence, this affirms that our classification model provides reproducible and consistent results. 


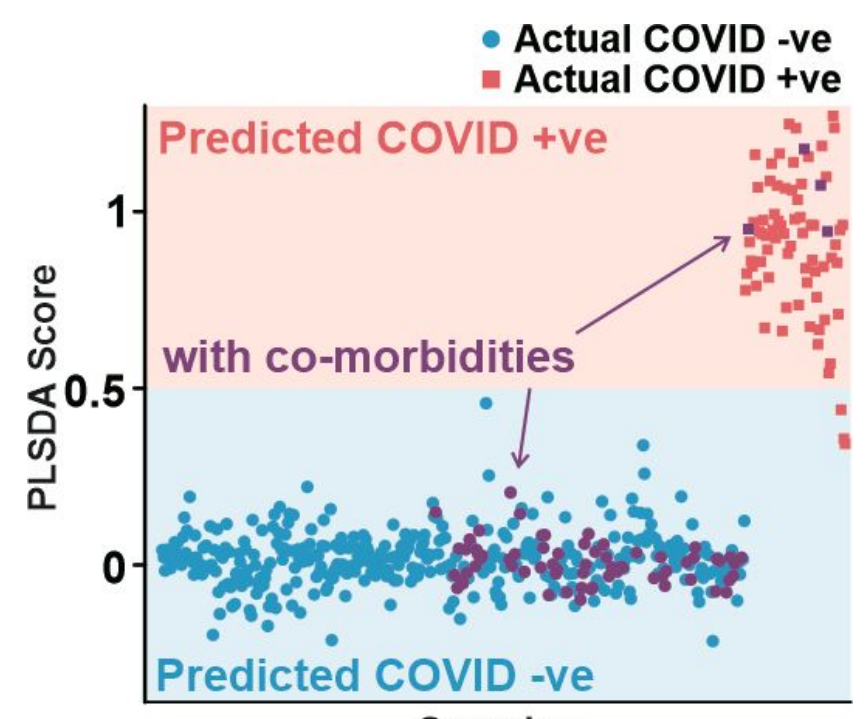

Samples

Figure S15. PLSDA score plot derived from the classification of individual SERS superprofiles. Participants with reported comorbidities are highlighted in purple, illustrating that the participants' existing health conditions do not affect their classification scores.

We would like to highlight that since the provision of this information is strictly voluntary, we do not have the information for all 501 trial participants. Nonetheless, the accurate classification of the 70 participants with reported comorbidities indicates that our SERS sensor is able to identify specific differences in participants' breath profiles that were directly linked to whether they had COVID-19 or not. 


\section{References}

1. Chen, L.; Sun, H.; Zhao, Y.; Zhang, Y.; Wang, Y.; Liu, Y.; Zhang, X.; Jiang, Y.; Hua, Z.; Yang, J., Plasmonic-Induced SERS Enhancement of Shell-Dependent $\mathrm{Ag} @ \mathrm{Cu}_{2} \mathrm{O}$ CoreShell Nanoparticles. RSC Adv. 2017, 7, 16553-16560.

2. Hu, J.; Zhao, B.; Xu, W.; Li, B.; Fan, Y., Surface-Enhanced Raman Spectroscopy Study on the Structure Changes of 4-Mercaptopyridine Adsorbed on Silver Substrates and Silver Colloids. Spectrochim. Acta, Part A 2002, 58, 2827-2834.

3. Jiang, L.; You, T.; Yin, P.; Shang, Y.; Zhang, D.; Guo, L.; Yang, S., Surface-Enhanced Raman Scattering Spectra of Adsorbates on $\mathrm{Cu}_{2} \mathrm{O}$ Nanospheres: Charge-Transfer and Electromagnetic Enhancement. Nanoscale 2013, 5, 2784-2789.

4. Sun, F.; Galvan, D. D.; Jain, P.; Yu, Q., Multi-Functional, Thiophenol-Based Surface Chemistry for Surface-Enhanced Raman Spectroscopy. Chem. Commun. 2017, 53, 4550-4561.

5. Zhang, L.; Weng, Y.-j.; Liu, X.; Gu, W.; Zhang, X.; Han, L., Fe(iii) Mixed IP ${ }_{6} @$ Au NPs with Enhanced SERS Activity for Detection of 4-ATP. Sci. Rep. 2020, 10, 5752.

6. Capocefalo, A.; Mammucari, D.; Brasili, F.; Fasolato, C.; Bordi, F.; Postorino, P.; Domenici, F., Exploring the Potentiality of a SERS-Active pH Nano-Biosensor. Front. Chem. 2019, 7 . 